\title{
Electron Field Emission Measurements from Boron-Doped CVD Diamond on Tantalum
}

\author{
J. A. N. Gonçalves, G. M. Sandonato, \\ Laboratório Associado de Plasma, Instituto Nacional de Pesquisas Espaciais \\ Caixa Postal 515, CEP 12201-970, São José dos Campos, SP, Brazil \\ and K. Iha \\ Instituto Tecnológico de Aeronáutica, Departamento de Química \\ 12228-900, São José dos Campos, SP, Brazil
}

Received on 12 March, 2002. Revised version received on 2 August, 2002

\begin{abstract}
Boron-doped polycrystaline diamond films grown by hot-filament-assisted chemical vapor deposition were studied with ultraviolet photoemission spectroscopy (UPS), Raman spectroscopy, X-ray diffractometry and current voltage measurements. The UPS measurement shows that the work function $(\phi)$ without electric field is about $3.9 \mathrm{eV}$. The field-emission current-voltage measurements indicate a threshold voltage ranging from $8.97 \times 10^{6}$ to $9.64 \times 10^{6} \mathrm{~V} / \mathrm{m}$ and a work function $(\phi)$ about $0.3 \mathrm{eV}$. These results show that boron doped diamond films exhibit a negative electron affinity in high electric field.
\end{abstract}

\section{Introduction}

Diamond possesses unique semiconductor properties, such as wide bandgap, high breakdown voltage, and both high electron and hole mobilities [1]. These properties make diamond attractive for application in high-frequency and highpower electronics. Boron doped diamond films have been prepared by various chemical vapor deposition (CVD) methods and some works have provided information on the structural, optical an electrical properties of the films [2-8].

Boron doped diamond is a p-type semiconductor, and it is the only dopant which has been successfully and reproducible used to prepare semiconductor diamond. Because of its small size, the boron atom is easily incorporated in the diamond lattice. The introduction of boron atoms would affect the structure and properties of the diamond films, so it is important to understand the nature of boron atoms in the diamond films for preparing semiconductor diamond.

In the present work, polycrystalline diamond films with high boron concentration were prepared on tantalum substrate by hot filament CVD method. The boron was introduced by $\mathrm{B}_{2} \mathrm{O}_{3}$ in methanol solution.

Scanning electron microscopy (SEM) and x-rays diffractometry (XDR) were employed to study the morphology and structure of these films. Raman spectroscopy, currentvoltage characteristics (IvsV) and ultraviolet photoemission spectroscopy (UPS) were used to investigate their optical and electrical properties.

\section{Experimental details}

The diamond films were grown on monocrystalline tantalum (111) by hot filament CVD in a $10 \mathrm{~cm}$ diameter and 30 $\mathrm{cm}$ high cylindrical quartz reactor. Boron was introduced in the reactor by flowing hydrogen through the $\mathrm{B}_{2} \mathrm{O}_{3}$ methanol solution.

The substrates were previously cleaned with acetone and scratched by a diamond paste (grain size of $1 \mu \mathrm{m}$ ) in order to promote a better nucleation of the diamond films. The diamond films were grown at $800^{\circ} \mathrm{C}$ from $0.5 \% \mathrm{H}_{2} / \mathrm{CH}_{4}$ mixture at a total pressure of $50 \mathrm{Torr}$. Boron oxide in methanol solution was used with $20000 \mathrm{ppm} \mathrm{B} / \mathrm{C}$ ratio.

A spectroscope Renishaw model RM 3000 was used for Raman spectroscopic investigations with an air cooled 785 $\mathrm{nm}$ laser diode (with an output power of $17 \mathrm{Mw}$ ) for excitation of the samples. The diffractograms were obtained using a spectrometer Phillips PW 1840 X-ray with a solid state goniometer, and equipped with $\mathrm{CuKa}$ (1.5406) cathode and nickel filter. The control parameters for the samples investigated are shown in Table 1.

Table 1. X-ray parameters for the sample investigated.

\begin{tabular}{ll}
\hline Power & $40 \mathrm{KV}$ e $250 \mathrm{~mA}$ \\
Step size $(2 \theta)$ & 0.020 \\
Number of steps & 5500 \\
Time per steps $(s)$ & 1.00 \\
Scan speed $(2 \theta / s)$ & 0.02 \\
Receiving slite & 0.2 \\
\hline
\end{tabular}


The first type of electron emission measurement employed was UPS wherein the ultraviolet light is incident on the conduction band [9]. Electrons with sufficient energy to overcome the electron affinity of the material are emitted into the vacuum. The second type of electron emission measurement was current-voltage characteristics $(I \times V)$. The $I \times V$ measurements were taken at two distances using an experimental setup specially developed to this purpose.

\section{Results}

The surface of the diamond film was observed by scanning electron microscopy (SEM). Figure 1 shows SEM micrograph of surface morphologies for boron doped diamond deposited on tantalum. Crystal facets are observed with a thickness of $15 \mu \mathrm{m}$ and grain sizes are $2 \mu \mathrm{m}$. Both thickness and grain sizes were obtained by SEM microscopy.

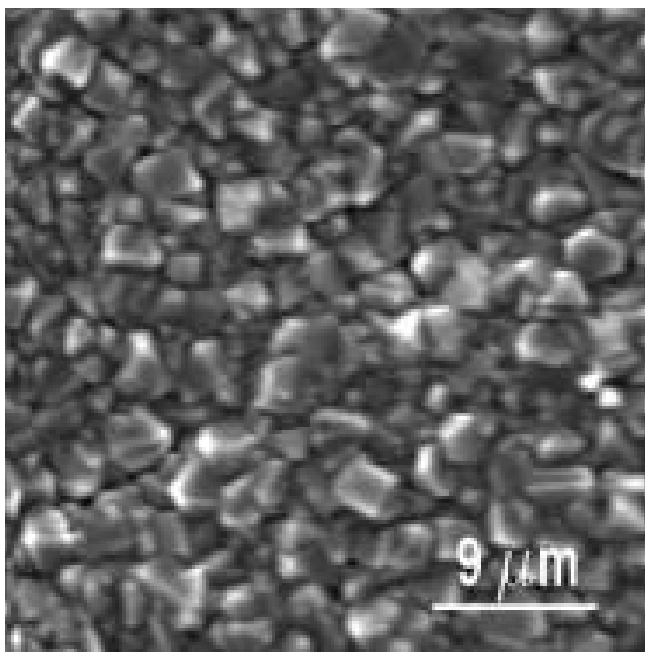

Figure 1. Scanning Electron Microscopy (SEM) of diamond film grown with $\mathrm{B} / \mathrm{C}$ of 20000 ppm.

Since Raman spectroscopy is a nondestructive method, it is commonly used in characterization of the structure and quality of synthesized diamond films [10]. A drastic change of Raman spectra of diamond film with high level of boron was observed. The results reveal that the peak intensity at $1332 \mathrm{~cm}^{-1}$, corresponding to the transversal mode (related to the $s p^{3}$ bound) of the diamond, decreases as the boron concentration increases [11]. Nevertheless, a wide band arises around $1220 \mathrm{~cm}^{-1}$ and increases as the boron concentration is increased, as shown in Fig. 2.

The same sample was investigated by x-ray diffractometry and the peaks related to the tantalum, tantalum carbide and diamond are shown in Figure 3. Although the tantalum substrate has no any preferential growing direction, it can be noted that the diamond peak of the plane (111) is more intense than the peak of the plane (220). This indicates that the growing process occurs preferentially at the plane (111), otherwise the orientation of the diamond films should be in the plane (110), i.e., in the transversal plane to the plane (111).

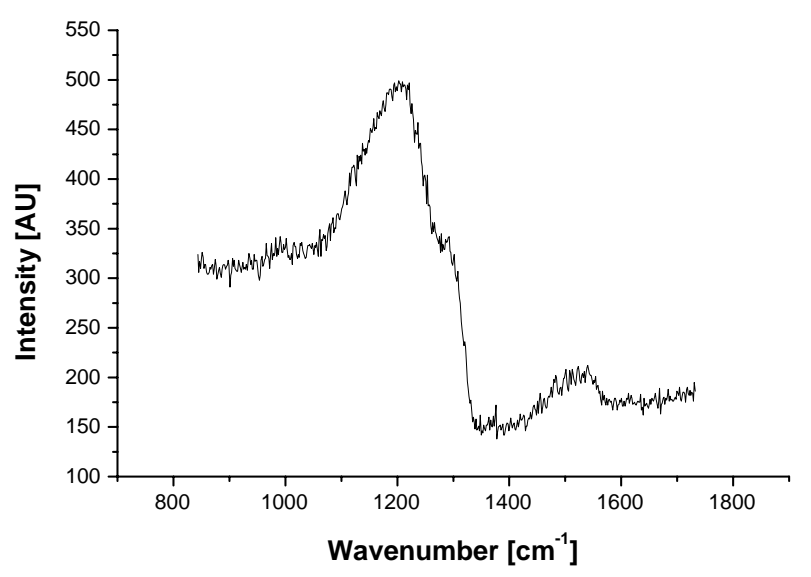

Figure 2. Raman spectroscopy of diamond films grown with B/C of $20000 \mathrm{ppm}$.

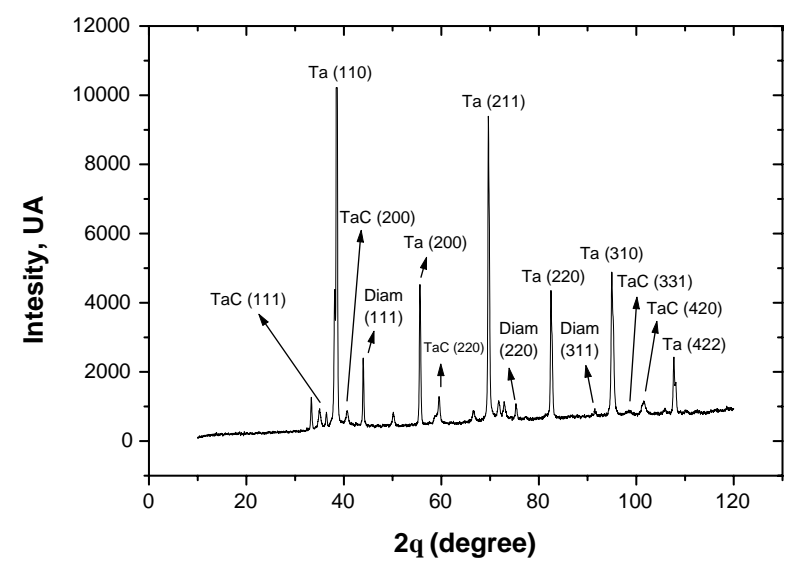

Figure 3. Typical XDR diffractogram of diamond film on tantalum.

UPS measurements were performed in the Linköping University, in an ultra high vacuum chamber (base pressure below $2 \times 10^{-10}$ Torr $)$. The sample excitation in this system was provided by $21.5 \mathrm{eV}$ light a helium resonance discharge lamp, and a hemispherical analyzer was used to measure the energy spectrum of the photoemitted electrons.

The UPS system is described in more details elsewhere [12]. The work function measured was $3.9 \mathrm{eV}$ for the boron doped diamond film.

Field emission measurements were obtained within high vacuum chamber (background pressure bellow $10^{-5}$ Torr) and the measurements were performed in the characterization system. The sample was placed and held in the proper compartment, and the movable anode was used for distance adjustment. The current-voltage measurements, taken at 50 $\mu \mathrm{m}$ and at $100 \mu \mathrm{m}$ apart from the cathode are shown in Figure 4. The sample area probed was the $10 \mathrm{~mm}$ in diameter. Field emission current-voltage measurement indicates threshold voltages of $8.97 \times 10^{6} \mathrm{~V} / \mathrm{m}$ for $50 \mu \mathrm{m}$ and $9.64 \times 10^{6} \mathrm{~V} / \mathrm{m}$ for $100 \mu \mathrm{m}$. 


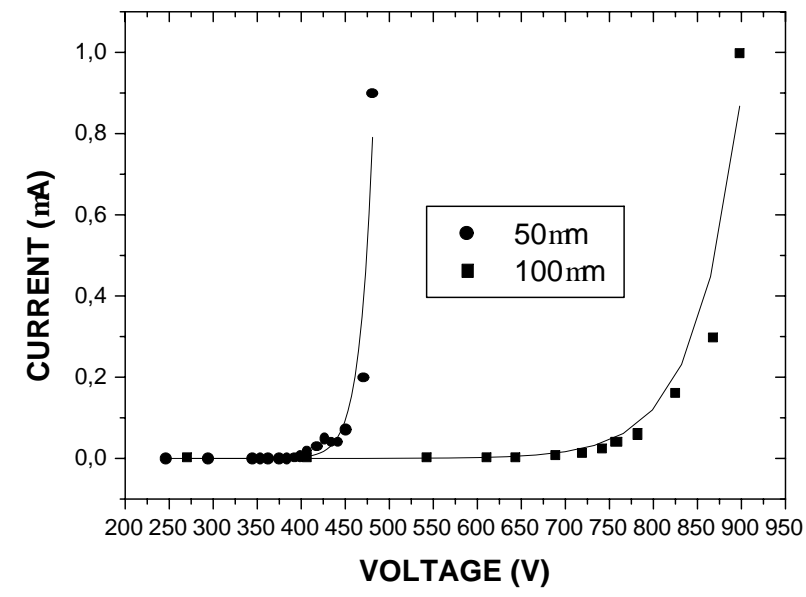

Figure 4. Current-voltage characteristics ploted as linear IvsV at room temperature.

These field emission results can be analyzed in terms of Fowler-Nordheim theory which describes the electron emission current via barrier tunneling [13]. The FowlerNordheim equation has the form:

$$
I=k\left(\frac{\beta V}{d}\right)^{2} \exp \left(\frac{-6530 d \phi^{\frac{3}{2}}}{\beta V}\right)
$$

where $k$ is a constant related to the emission area, $V$ is the voltage applied, $\phi$ is the work function, $\beta$ is the geometric field enhancement factor and $d$ is the distance from anode to the cathode. The experimental values of $\ln \left(I V^{-2}\right)$ were plotted against $V^{-1}$, and the slope of the straight line gives the work function $(\phi)$ values of 0.396 and $0.306 \mathrm{eV}$ for the distances of $50 \mu \mathrm{m}$ and $100 \mu \mathrm{m}$, respectively, as shown in Fig. 5. The work function values obtained are in agreement with the emission characteristics of boron doped diamond cathodes [13].

\section{Conclusion}

The downshifts of both Raman peaks at $1332 \mathrm{~cm}^{-1}$ and at $1220 \mathrm{~cm}^{-1}$ were attributed to the boron incorporation in the diamond film. The investigations by $\mathrm{X}$-ray diffractometry have revealed the occurrence of $T a C$ in the diamond film and the growing process occurs preferentially at the plane (111), as shown in Fig. 3.

Ultraviolet photoemission spectroscopy (UPS) indicates the sample posses work function of the $3.9 \mathrm{eV}$ with no electric field applied. When an intense electric field is applied, the work function downshifts to $0.3 \mathrm{eV}$. This fact shows that the boron doped diamond film exhibits field emission comportment with threshold voltages ranging from $8.97 \times 10^{6}$ to $9.64 \times 10^{6} \mathrm{~V} / \mathrm{m}$, for the cathode/anode distances of $50 \mu \mathrm{m}$ and $100 \mu m$ respectively.
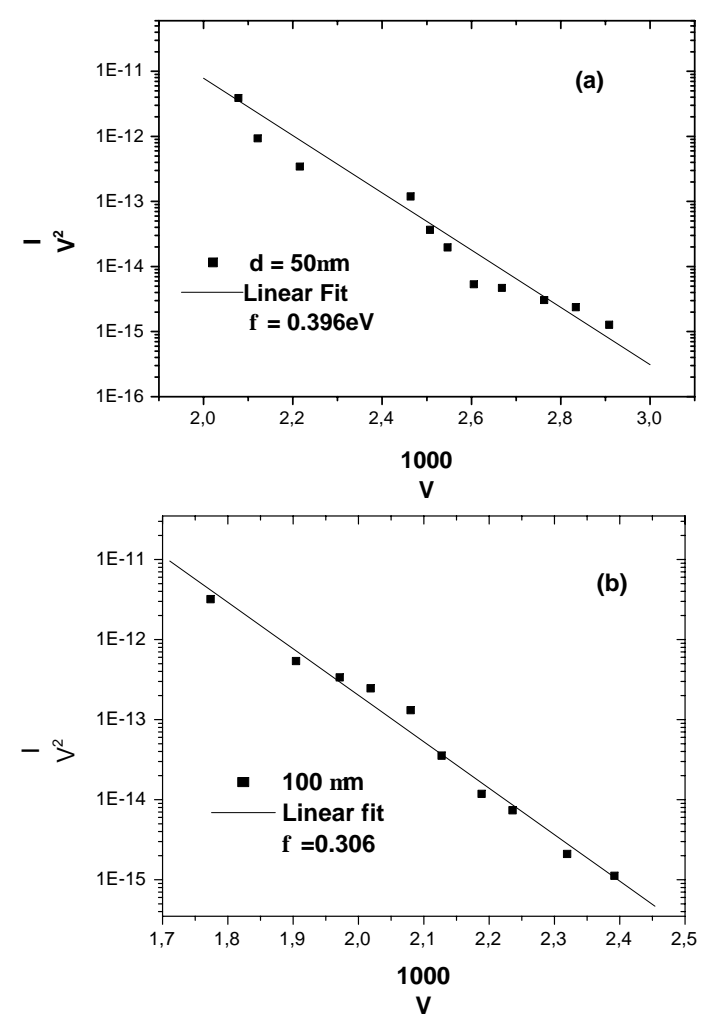

Figure 5. Fowler-Nordheim plot of the field emission (a) for 50 $\mu \mathrm{m}$ distance cathode-anode and (b) for $100 \mu \mathrm{m}$ distance cathodeanode.

\section{Acknowledgement}

We would like to express our thanks to Dr E. J. Corat and V. T. Airoldi for their help in the synthesis of diamond films.

This work has been supported by the Fundação de Amparo a Pesquisa do Estado de São Paulo (FAPESP)

\section{References}

[1] J. Wilks and E. Wilks, Properties an Application of Diamond, Butterworth-Heinemann, Oxford, 1991.

[2] J. Mort, M. A. Machonkin, and K. Okumura, Appl. Phys. Lett. 58, 1908 (1991).

[3] K. Nishimura, K. Das, and J. T. Glass, J. Appl. Phys. 69, 3142 (1991).

[4] X. H. Wang, G. H. M. Ma, W. Zhu, J. T. Glass, L. Bergman, K. F. Turner, and R. J. Nemanich, Diamond Related Mater. 1, 828 (1992).

[5] Y. San, Z. Guangtian, and J. Zengsun, Chin. J. Semicond. 14, 580 (1993).

[6] M. Werner, O. Dorsch, H. U. Baerwind, E. Obermeier, L. Haase, W. Seifert, A. Ringhandt, C. Johnston, S. Romani, H. Bishop, and P. R. Chalker, Appl. Phys Lett. 64, 595 (1994).

[7] R. Locher, J. Wagner, F. Fuchs, M. Maier, P. Gonon, and P. Koidl, Diamond Rel. Mater. 4, 678 (1995).

[8] R. Locher, J. Wagner, F. Fuchs, C. Wild, P. Hiesinger, P. Gonon, and P. Koidl, Mater. Sci. Eng. B 29, 211 (1995). 
[9] A. Zangwill, Physics at Surfaces, Cambridge University Press, Cambridge, 1998.

[10] K. Miyata, K. Kumagai, K. Nishimura, and K. Kobashi, J. Mater. Res. 8, 35 (1993).

[11] L. H. Robins, E. N. Farabaugh, and A. Feldiman, In Diamond Optics IV, 22-23 July 1991, San Diego, CA. Belling- ham, Wash. SPIE, 105.

[12] J. van der Weide, Z. Zhang, P. K. Baumann, M. G. Wensell, J. Bernholc, and R. J. Nemanich, Phys. Rev. B50, 5803 (1994).

[13] R. Gomer, Field Emission and Field Ionization, Harvard University Press, Cambridge, MA, 1961. 